\title{
Criatividade no Ensino Fundamental: Fatores Inibidores e Facilitadores segundo Gestores Educacionais ${ }^{1}$
}

\author{
Eunice M. L. Soriano de Alencar ${ }^{2}$ \\ Denise de Souza Fleith \\ Universidade de Brasília \\ Evely Boruchovitch \\ Universidade Estadual de Campinas \\ Clarissa Nogueira Borges \\ Universidade de Brasília
}

\begin{abstract}
RESUMO - Este estudo investigou a percepção de gestores de instituições de ensino fundamental sobre fatores que dificultam o professor promover o desenvolvimento da criatividade discente e procedimentos que poderiam utilizar para apoiar o professor na promoção da criatividade em sala de aula. Participaram 118 gestores de escolas públicas e particulares, os quais responderam a uma checklist de barreiras à criatividade em sala de aula e quatro questões abertas. Fatores inibidores mais apontados foram: desconhecimento pelo professor de práticas pedagógicas que poderiam ser utilizadas para propiciar o desenvolvimento da criatividade dos alunos e falta de entusiasmo pela atividade docente. Orientação, apoio e incentivo ao docente foi o procedimento mais apontado pelos gestores para auxiliar o professor a desenvolver a criatividade de seus alunos.
\end{abstract}

Palavras-chave: criatividade, gestor educacional, práticas pedagógicas

\section{Creativity in Elementary School: Inhibiting and Facilitating Factors according to School Principals}

\begin{abstract}
This study investigated the perception of school principals regarding factors that hamper teachers to promote the development of student's creativity and strategies that the school principal could use to support teachers in the promotion of creativity in the classroom. The participants were 118 school principals from public and private schools, who completed a checklist of obstacles to creativity in the classroom and four open questions. The most frequent obstacles pointed out were teachers' lack of knowledge of pedagogical practices to favor the development of students' creativity and teacher's lack of enthusiasm. Guidance, support and incentive to teachers were the most frequently pointed out procedures to assist the teacher in fostering the creativity of their students.
\end{abstract}

Keywords: creativity, school principal, teaching practices

O desenvolvimento do potencial criador como objetivo educacional tem sido destacado em diretrizes governamentais (Ministério da Educação, 1997, 1998, 2004, 2010; SmithBingham, 2006) e recomendado por pesquisadores em diferentes países (Alencar \& Fleith, 2009; Craft, 2006; Kaufman \& Sternberg, 2006; Wechsler \& Souza, 2011). Várias são as razões para justificar o interesse pela promoção, no contexto escolar, da criatividade, ou seja, da capacidade de se produzir algo novo, como uma ideia, um poema, uma composição musical, considerado satisfatório ou de valor por um número significativo de pessoas (Alencar \& Fleith, 2009). Uma dessas razões diz respeito à necessidade de o aluno ser preparado para o cenário incerto e complexo do século XXI, o qual requer alta habilidade de resolução de novos problemas aliada a um conjunto de atributos personológicos que se associam à criatividade. Neste sentido, estabelecer como um dos objetivos curriculares o desenvolvimento da competência criativa é uma das maneiras de preparar os estudantes para um

1 Apoio: $\mathrm{CNPq}$

2 Endereço para correspondência: SHIS QL 10, conjunto 6, casa 14, Brasília, DF, Brasil. CEP: 71630-065 E-mail: eunices.alencar@gmail. com futuro incerto (Beghetto, 2010). Outra razão é por serem as experiências criativas de aprendizagem uma via para o bemestar emocional, contribuindo positivamente para a qualidade de vida do indivíduo. Também tem sido ressaltado o efeito positivo de práticas pedagógicas promotoras da criatividade na motivação do aluno para a aprendizagem (Cropley, 2005; Fleith \& Alencar, 2010). O mais comum em ambientes da escola, especialmente na sala de aula regular, tem sido alunos pouco motivados, entediados com as tarefas propostas e com dificuldade de concentração. Isso em parte é explicado pela ênfase na reprodução e repetição de conteúdos, limitadas oportunidades para expressão de ideias e supressão da autonomia discente. Métodos instrucionais que abrem espaço para a expressão criativa contribuiriam para elevar os níveis motivacionais dos estudantes (Amabile, 1996; Fleith \& Alencar, 2010; Fredricks, Alfeld, \& Eccles, 2010), sendo tais métodos apontados por Renzulli (1992) como um dos facilitadores do desenvolvimento da produtividade criativa discente.

Embora se reconheça a importância da criatividade e de um ambiente educacional em que haja espaço e clima adequado (Amabile, 1996) para sua expressão, constata-se que o seu desenvolvimento tem recebido atenção limitada nos 
distintos níveis de ensino. Segundo Alencar (2007), vários fatores contribuem para esse cenário. Alguns desses fatores têm sua origem em valores profundamente arraigados no contexto sociocultural, como a resistência à mudança e à introdução de inovações que se observa em distintos setores da sociedade, incluindo a instituição escolar. Outros espelham a cultura da escola, na qual a pressão ao conformismo ocupa um lugar central, observando-se críticas aos professores que buscam inovar as suas práticas pedagógicas, dificultandoos ou mesmo impedindo-os de adotar uma prática que se caracteriza pela promoção da criatividade. O mais comum são procedimentos de ensino convergentes, centrados no professor, com poucas oportunidades para o aluno expressar suas ideias, interpretações e insights. Ademais, criatividade e estratégias para o seu desenvolvimento não são tópicos focalizados na grande maioria dos cursos de formação de professores, como apontado por diversos autores e constatado em pesquisas (Martínez, 2006; Oliveira \& Alencar, 2007; Souza \& Alencar, 2006; Wechsler, 2001). Observa-se ainda que ideias sem sustentação científica a respeito da criatividade são compartilhadas por muitos educadores (Alencar \& Fleith, 2009; Cropley, 2005; Jackson, Oliver, Shaw, \& Wisdom, 2006). Uma delas é a concepção da criatividade como um talento natural, apresentado apenas por poucos indivíduos. Outra é a crença de que a expressão criativa ocorreria independentemente das condições ambientais, predominando uma concepção unilateral da criatividade, como um fenômeno de caráter intrapsíquico, subestimando-se a significativa influência da escola e da sociedade em seu desenvolvimento e expressão.

Embora seja o professor um dos principais agentes do contexto escolar e elemento chave para o fomento da criatividade em sala de aula, ele integra uma equipe de profissionais que devem estar ativamente envolvidos em assistir o professor em sua prática pedagógica. Um desses profissionais é o gestor da instituição educacional. Este também muito pode contribuir para assegurar ações educativas que favoreçam o desenvolvimento e expressão da criatividade, tanto dos estudantes quanto dos demais partícipes da instituição escolar, dado o seu papel central, como lembra Lücke (2000), na promoção de práticas e da organização escolar, devendo suas ações sustentar o bom andamento das atividades previstas. Nota-se que a literatura registra vários estudos referentes a elementos facilitadores e inibidores à expressão criativa discente junto a professores de distintos níveis de ensino. Carvalho e Alencar (2004), por exemplo, levantaram dados referentes a elementos facilitadores e cerceadores junto a professores de Geografia de 5a a 8a séries, tendo constatado que as práticas pedagógicas apontadas pelos professores como as que melhor favorecem o desenvolvimento da criatividade discente estavam mais relacionadas a procedimentos que facilitam a aprendizagem de conteúdo, ao passo que os fatores inibidores mais indicados eram relativos ao aluno, o que também foi constatado por Vianna e Alencar (2006), entre tutores de cursos de educação online. De forma similar, Mariani e Alencar (2005), em estudo com professores de História que foram entrevistados a respeito de elementos que impedem ou limitam a expressão criativa em sua atividade docente e aqueles que se constituem em estímulos, observaram que foram as características do aluno, como falta de motivação, participação, compromisso, agressividade e timidez, o aspecto mais frequentemente ressaltado como limitador, e entre os facilitadores a liberdade e paixão pelo trabalho. Alencar e Fleith (2008), em estudo com professores de 1a a 4 a séries do ensino fundamental, encontraram que as barreiras mais frequentemente apontadas pelos professores para a promoção de condições favoráveis à criatividade em sala de aula referiam-se aos alunos, como elevado número de alunos em sala de aula e alunos com dificuldades de aprendizagem. Resultados similares foram obtidos em outra investigação com professores da educação superior (Alencar \& Fleith, 2010).

Uma análise da literatura sobre criatividade no contexto educacional sinaliza, entretanto, escassez de estudos empíricos com amostras de gestores de instituições educacionais focalizando criatividade no contexto escolar, embora alguns autores (Alencar, 2007; Ediger, 2001; Smith \& Smith, 2010) tenham chamado a atenção para o papel do gestor na promoção da criatividade na escola. Foi localizada apenas uma pesquisa com gestores em que foram identificados elementos inibidores e facilitadores à expressão da criatividade no contexto escolar (Oliveira \& Alencar, 2010). Nesse estudo, nove gestores de instituições educacionais foram entrevistados, explorando-se suas concepções de criatividade, elementos que interferem na implantação de práticas pedagógicas voltadas para o desenvolvimento da criatividade no contexto escolar, e aqueles que facilitam ou inibem, no exercício da função de gestor, uma intervenção no sentido de promover condições favoráveis ao desenvolvimento da criatividade na escola e de seus integrantes. Notou-se que esses profissionais consideravam a criatividade importante. Apontaram vários elementos inibidores ao desenvolvimento da criatividade no contexto escolar, tendo sinalizado especialmente elementos referentes ao professor, como desestímulo, desânimo, falta de comprometimento, falta de capacitação profissional, medo do novo, além de outros de natureza administrativa, como rotatividade de professores, falta de material, rigidez das normas, burocracia e insuficiência de políticas de investimentos na escola. Quanto aos elementos que promovem o uso de práticas pedagógicas facilitadoras da expressão criativa, os mais apontados diziam respeito ao docente, como prazer em ensinar e interesse e disposição do docente para inovar, embora tenham sido sinalizados também outros de natureza administrativa, como constância da equipe pedagógica e direção e equipe atuando conjuntamente para o desenvolvimento da criatividade.

Tendo em vista a relevância do tema, a escassez de estudos sobre criatividade focalizando o papel do gestor de instituições educacionais, e ainda levando em conta que a identificação de barreiras e elementos facilitadores à promoção da criatividade discente poderia ser útil na organização de programas de preparação de professores e dos demais membros da equipe pedagógica para o fomento de uma cultura de criatividade na instituição escolar, desenvolveu-se este estudo com o objetivo de investigar: (a) fatores percebidos por gestores de instituições educacionais do ensino fundamental como entraves que dificultam ao professor promover o desenvolvimento da criatividade 
discente; (b) procedimentos que gestores consideram que poderiam utilizar para apoiar o professor na promoção de condições favoráveis à criatividade em sala de aula; e (c) possíveis diferenças entre gestores das instituições de ensino públicas e particulares nas variáveis pesquisadas.

\section{Método}

\section{Participantes}

Participaram do estudo 118 gestores de instituições de ensino fundamental, sendo $26(22,0 \%)$ do sexo masculino e $92(78,0 \%)$ do sexo feminino. Noventa e seis $(81,4 \%)$ trabalhavam em escolas públicas e os demais $(n=22 ; 18,6 \%)$ em escolas particulares de distintas regiões administrativas do Distrito Federal. A idade desses participantes variou de 27 a 66 anos $(M=40,08 ; D P=8,66)$, com tempo de experiência na função variando entre 1 a 40 anos $(M=7,56 ; \mathrm{DP}=7,20)$. Quanto ao grau de escolaridade, $32(27,1 \%)$ informaram ter concluído curso superior, $80(67,8 \%)$ ter cursado especialização e 5 o mestrado. Três deixaram de indicar a idade, oito o tempo de experiência na função e um o seu grau de escolaridade.

\section{Instrumento e Procedimento de Coleta de Dados}

Foi utilizado um questionário composto de três partes. A primeira para levantamento de dados biográficos dos respondentes (gênero, idade, experiência docente e em gestão de instituições de ensino, formação acadêmica) e obter informações a respeito do tipo e local da escola em que trabalhavam. A segunda, composta por uma checklist com distintos fatores que podem constituir barreiras à promoção da criatividade discente pelo professor, com instrução aos participantes para assinalar aqueles com que concordavam serem entraves a tal promoção. A mesma foi utilizada anteriormente por Alencar e Fleith (2008) em um estudo com professores do ensino fundamental e inclui distintos itens referentes ao aluno, ao professor, ao currículo e à escola, entre outros aspectos. Essa checklist foi construída com base em estudos teóricos e empíricos a respeito de fatores facilitadores e inibidores à criatividade no contexto educacional (Alencar, 1995, 2001; Alencar \& Fleith, 2009; Cropley, 1997; Fleith, 2000; Mariani, \& Alencar, 2004; Morgan \& Foster, 1999; Torrance 1995). A terceira parte incluiu as seguintes questões abertas:

1. Em sua opinião, o que um gestor de instituição de ensino pode fazer para apoiar o professor na promoção de um ambiente em sala de aula propício ao desenvolvimento da criatividade do aluno?

2. Que práticas pedagógicas o(a) senhor(a) considera que o professor poderia utilizar para favorecer o desenvolvimento da criatividade do aluno?

3. O projeto pedagógico desta instituição contempla a promoção da criatividade do aluno? Em caso positivo, explicite o que o projeto sinaliza a esse respeito.
4. Como eliminar os fatores que o(a) senhor(a) considera que têm dificultado ao professor favorecer o desenvolvimento da capacidade de criar de seus alunos?

O questionário incluía também uma checklist composta por um conjunto de itens sobre possíveis entraves à motivação do aluno para o estudo e aprendizagem e duas questões abertas, uma delas referente ao que fazem os "bons" professores fazem para motivar os alunos, e a outra relativa ao que fazem os "maus" professores para desmotivar os alunos. Os dados obtidos sobre estes aspectos encontram-se em Boruchovitch, Alencar, Fleith e Fonseca (2013).

Antes de sua aplicação na amostra do presente estudo, foi realizado um estudo piloto com dois gestores, no sentido de se garantir a clareza das instruções e identificar possíveis mudanças na estrutura do conteúdo do instrumento de pesquisa. Não foram identificadas correções ou mudanças necessárias no questionário, o qual foi considerado adequado para a coleta de dados.

Os dados foram coletados pela primeira pesquisadora e por estudantes de pós-graduação e bolsistas de Iniciação Científica. Embora tivesse sido prevista a aplicação do instrumento de forma individual na presença do pesquisador, nem sempre esta presença ocorreu, dada a incompatibilidade de horário participante/pesquisador. Ademais, uma das aplicações se deu durante um encontro de gestores, promovido por uma Diretoria Regional de Ensino do Distrito Federal. Essa foi feita pela primeira autora, que se disponibilizou a esclarecer as dúvidas referentes ao conteúdo do questionário. A participação no estudo foi voluntária, tendo sido assegurado aos participantes o caráter confidencial das respostas fornecidas e informado que os dados seriam analisados coletivamente, cumprindo assim as exigências éticas legais.

\section{Análise dos Dados}

Foram calculadas a frequência e porcentagem em cada item da checklist (total e por tipo de instituição de ensino). $\mathrm{O}$ qui-quadrado foi utilizado para análise das diferenças entre gestores de instituições públicas e particulares.

Para análise das questões abertas, foi utilizada análise de conteúdo, seguindo as orientações de Bardin (2004). Foi efetuada a categorização das respostas por meio de classificação das unidades de significação, levantando-se, a seguir, a sua frequência e porcentagem. Após a construção inicial de categorias e levantamento de suas respectivas frequências por um dos membros da equipe de pesquisa, uma segunda análise foi feita pela primeira autora deste artigo, quando se diminuiu o número de categorias propostas e se reavaliou(reavaliaram) a(s) categoria(s) na(s) qual(quais) melhor se enquadravam algumas respostas dos participantes. Após esta etapa, reuniram-se novamente os participantes da equipe, com vistas a discutir possíveis discrepâncias na classificação de algumas respostas, buscando um acordo. 


\section{Resultados}

Constatou-se, como apresentado na Tabela 1, que os fatores inibidores mais apontados pelos gestores à promoção do desenvolvimento da criatividade dos alunos pelo professor foram: desconhecimento pelo professor de práticas pedagógicas que poderiam ser utilizadas para propiciar o desenvolvimento da criatividade dos alunos $(n=83 ; 70,3 \%)$; falta de entusiasmo pela atividade docente $(n=77 ; 65,3 \%)$; elevado número de alunos em sala de aula $(n=74 ; 62,7 \%)$; insegurança para testar novas práticas pedagógicas $(n=64$; $54,22 \%$ ); e desconhecimento de textos (livros e/ou artigos) a respeito de como implementar a criatividade em sala de aula $(n=64 ; 54,2 \%)$. Nota-se que os fatores menos apontados pelos gestores foram: qualidade dos livros didáticos adotados na escola $(n=19 ; 16,1 \%)$; extensão do programa a ser cumprido no decorrer do ano letivo $(n=25 ; 21,2 \%)$; poucas oportunidades para o professor discutir e trocar ideias com colegas sobre estratégias instrucionais ( $n=29 ; 24,6 \%$ ); e falta de autonomia na forma de conduzir as atividades docentes $(n=30 ; 25,4 \%)$.

A análise das respostas de gestores de instituições públicas e particulares de ensino à primeira questão aberta "Em sua opinião, o que um gestor pode fazer para apoiar o professor do ensino fundamental na promoção de um ambiente em sala de aula propício ao desenvolvimento da criatividade do aluno?" resultou em seis categorias, denominadas Orientação/Apoio/ Incentivo; Formação/Capacitação; Recursos Didáticos e Materiais; Discussão/Troca de Experiências; Alunos; e Outras (ver Tabela 2). Observa-se que as duas categorias com maior número de respostas por parte dos gestores de instituições públicas de ensino foram Orientação/Apoio/
Incentivo $(f=44)$ e Recursos Humanos, Didáticos e Materiais $(f=37)$. Em relação aos gestores de instituições particulares, por outro lado, as categorias com maior número de respostas foram Orientação/Apoio/Incentivo $(f=16)$ e Formação/ Capacitação $(f=10)$. Onze gestores de instituições públicas deixaram de responder a questão e a resposta de um gestor não correspondeu ao que foi perguntado.

Respostas que ilustram as distintas categorias são apresentadas a seguir.

\section{Orientação/Apoio/Incentivo}

No dia-a-dia, valorizar as iniciativas e projetos desenvolvidos na escola, para que seja um impulso e incentivo para continuar desenvolvendo novas práticas.

Ouvir o professor e dar instruções sobre formas criativas de tornar o ensino mais interessante.

Estar mais presente, atento, participativo no apoio didático e pedagógico junto aos professores.

\section{Formação/Capacitação}

Oferecer condições para que o professor esteja em permanente processo de atualização de suas práticas pedagógicas.

Capacitar o professor, com grupos de estudos, realização de debates e cursos sobre o assunto.

Realizar a capacitação continuada.

\section{Recursos Humanos/Didáticos/Materiais}

Propiciar ao educador condições favoráveis ao desempenho de suas funções do ponto de vista material (recursos didáticos, novas tecnologias aplicadas à educação).

Tabela 1. Fatores que Dificultam ao Professor Promover o Desenvolvimento da Criatividade dos Alunos Segundo Gestores de Instituições de Ensino $(N=118)$

\begin{tabular}{|c|c|c|}
\hline Barreiras & f & $\%$ \\
\hline $\begin{array}{l}\text { Desconhecimento de práticas pedagógicas que poderiam ser utilizadas para propiciar o desenvolvimento da } \\
\text { criatividade dos alunos. }\end{array}$ & 83 & 70,3 \\
\hline Falta de entusiasmo pela atividade docente. & 77 & 65,3 \\
\hline Elevado número de alunos em sala de aula. & 74 & 62,7 \\
\hline Insegurança para testar novas práticas pedagógicas. & 64 & 54,2 \\
\hline Desconhecimento de textos (livros e/ou artigos) a respeito de como implementar a criatividade em sala de aula. & 64 & 54,2 \\
\hline Baixo reconhecimento do trabalho do professor. & 54 & 45,8 \\
\hline Falta de apoio institucional na implementação de projetos inovadores. & 54 & 45,8 \\
\hline Alunos com dificuldades de aprendizagem em sala de aula. & 52 & 44,1 \\
\hline Presença de alunos indisciplinados que perturbam o trabalho docente. & 50 & 42,4 \\
\hline Baixo incentivo para inovar a prática docente. & 49 & 41,5 \\
\hline Desinteresse do aluno pelo conteúdo ministrado. & 48 & 40,7 \\
\hline Escassez de material didático disponível na escola. & 44 & 37,3 \\
\hline Falta de oportunidade para realizar atividades fora da sala de aula. & 34 & 28,8 \\
\hline $\begin{array}{l}\text { Falta de orientação por parte da coordenação pedagógica da escola no que diz respeito a como favorecer o } \\
\text { desenvolvimento da criatividade do aluno. }\end{array}$ & 34 & 28,8 \\
\hline Falta de autonomia na forma de conduzir as atividades docentes. & 30 & 25,4 \\
\hline Poucas oportunidades para discutir e trocar ideias com colegas sobre estratégias instrucionais. & 29 & 24,6 \\
\hline Extensão do programa a ser cumprido no decorrer do ano letivo. & 25 & 21,2 \\
\hline Qualidade dos livros didáticos adotados na escola. & 19 & 16,1 \\
\hline
\end{tabular}


Tabela 2. Frequência e Porcentagem de Respostas à Primeira Questão Aberta por Parte de Gestores de Instituições Públicas e Particulares de Ensino Fundamental

\begin{tabular}{|c|c|c|c|c|c|c|}
\hline \multirow{3}{*}{ Categorias } & \multicolumn{4}{|c|}{ Tipo de Escola } & \multirow{2}{*}{\multicolumn{2}{|c|}{$\begin{array}{c}\text { Total } \\
(n=118)\end{array}$}} \\
\hline & \multicolumn{2}{|c|}{$\begin{array}{c}\text { Pública } \\
(n=96)\end{array}$} & \multicolumn{2}{|c|}{$\begin{array}{c}\text { Particular } \\
(\mathrm{n}=22)\end{array}$} & & \\
\hline & $f$ & $\%$ & $f$ & $\%$ & $f$ & $\%$ \\
\hline Orientação/Apoio/Incentivo & 44 & 30,35 & 16 & 31,37 & 60 & 30,61 \\
\hline Formação/Capacitação & 18 & 12,41 & 10 & 19,61 & 28 & 14,29 \\
\hline Recursos Humanos/ Didáticos/ Materiais & 37 & 25,52 & 8 & 15,69 & 45 & 22,96 \\
\hline Discussão/Troca de experiências & 25 & 17,24 & 5 & 9,80 & 30 & 15,31 \\
\hline Alunos & 3 & 2,07 & 3 & 5,88 & 6 & 3,06 \\
\hline Outras & 18 & 12,41 & 9 & 17,65 & 27 & 13,77 \\
\hline Total & 145 & 100 & 51 & 100 & 196 & 100 \\
\hline
\end{tabular}

Tabela 3. Frequência e Porcentagem de Respostas à Primeira Questão Aberta por Parte de Gestores de Instituições Públicas e Particulares de Ensino Fundamental

\begin{tabular}{|c|c|c|c|c|c|c|}
\hline \multirow{3}{*}{ Categorias } & \multicolumn{4}{|c|}{ Tipo de Escola } & \multirow{2}{*}{\multicolumn{2}{|c|}{$\begin{array}{c}\text { Total } \\
(n=118)\end{array}$}} \\
\hline & \multicolumn{2}{|c|}{$\begin{array}{c}\text { Pública } \\
(n=96)\end{array}$} & \multicolumn{2}{|c|}{$\begin{array}{c}\text { Particular } \\
(n=22)\end{array}$} & & \\
\hline & $f$ & $\%$ & $f$ & $\%$ & $f$ & $\%$ \\
\hline Atividades Diversificadas & 64 & 47,76 & 8 & 21,05 & 72 & 41,86 \\
\hline Recursos Didáticos/Materiais & 17 & 12,69 & 7 & 18,42 & 24 & 13,95 \\
\hline Aluno & 25 & 18,66 & 10 & 26,32 & 35 & 20,35 \\
\hline Outras & 28 & 20,89 & 13 & 34,21 & 41 & 23,84 \\
\hline Total & 134 & 100 & 38 & 100 & 172 & 100 \\
\hline
\end{tabular}

Disponibilizar materiais necessários: vídeos, TV, som, livros, cópias etc.

\section{Discussão/Troca de Experiência}

Reuniões para troca de ideias e conhecimentos de cada turma, para levantar as necessidades das mesmas.

Oportunizar a reflexão e a troca de experiências entre os educadores.

Encontros sistemáticos para estudos, avaliação, reavaliação, planejamento nas séries e no coletivo de todas as séries.

\section{Alunos}

Apoiar o desenvolvimento de práticas pedagógicas que tenham como referência o aluno como foco central da elevação da qualidade.

Ouvir a opinião dos principais envolvidos, os alunos.

Promover o diagnóstico dos alunos.

\section{Outras}

Buscar parceiros.

Proporcionar um ambiente favorável às relações humanas.

O professor só poderá incentivar a criatividade do aluno se o próprio professor for criativo.

$\mathrm{Na}$ segunda questão aberta, foi solicitado aos gestores para apontar práticas pedagógicas que o professor poderia utilizar para favorecer o desenvolvimento da criatividade do aluno. A análise das respostas obtidas levou à identificação de quatro categorias, elencadas na Tabela 3, denominadas
Atividades Diversificadas; Recursos Didáticos/Materiais; Alunos; e Outras. Como pode ser observado na tabela, Atividades Diversificadas foi a categoria que aglutinou maior número de respostas, dadas predominantemente por gestores de instituições públicas. Quinze gestores de instituições públicas não responderam a questão.

Respostas que ilustram as distintas categorias são apresentadas a seguir.

\section{Atividades Diversificadas}

Projetos que possam envolver arte e música, porque são atividades diferentes do cotidiano do aluno, despertando assim um maior interesse do aluno em vir e permanecer na escola, fazendo com que as atividades do dia-a-dia se tornem mais interessantes.

Desafios; olimpíada do conhecimento; feiras culturais.

Aulas concretas, visitas, passeios pedagógicos.

\section{Recursos Didáticos/Materiais}

Uso de multimídia; jogos; dinâmicas.

Utilização de materiais para motivação do aluno, como: materiais audiovisuais; histórias para que dêem início ou meio ou fim; materiais como jogos, caça-palavras, cruzadinha.

\section{Aluno}

Permitir que o aluno exponha seus anseios em relação ao ensino e à escola.

Desenvolver aulas com os alunos e não 'dar' aulas aos alunos, desafiando-os. Expor menos conteúdos e por os 
alunos pra trabalhar mais. Participação do aluno na sua avaliação.

\section{Outras}

Adotar aulas de reforço em turno contrário.

O diálogo aliado a técnicas de desenvolvimento da afetividade, pois quando se estabelecem vínculos entre o docente e a turma tudo mais se consegue alcançar.

O professor deve se preocupar em tornar o ensino mais eficiente e qualitativo.

$\mathrm{Na}$ terceira questão, foi perguntado aos gestores se o projeto pedagógico de sua instituição contemplava a promoção da criatividade do aluno e o que o projeto sinalizava a esse respeito. Foram obtidas respostas afirmativas a essa questão por parte de $62(64,58 \%)$ gestores de instituições públicas e $21(95,45 \%)$ de instituições particulares. Os demais gestores $(n=35)$ responderam negativamente, informaram que o projeto ainda não foi colocado em prática ou deixaram de responder a questão. A análise das respostas levou à identificação de quatro categorias, denominadas Atividades Diversificadas; Alunos; Professor; e Outras (ver Tabela 4). De forma similar ao observado nas questões abertas anteriores, constatou-se uma predominância de respostas na categoria Atividades Diversificadas. Ademais, apenas duas respostas tiveram como foco central o professor.
Seguem respostas que ilustram as distintas categorias. Atividades Diversificadas

Componentes curriculares (artes e informática educativa) instrumentais de várias outras atividades pedagógicas têm por meta desenvolver a imaginação, a criatividade e a expressão.

Oficina de esportes, oficina de informática, dança e ciências, xadrez, coral, rádio, jornal e práticas desportivas.

\section{Aluno}

O projeto visa mais a independência e autonomia do aluno. A partir daí, a criatividade é propiciada.

O projeto explicita ações que promovem a participação ativa do aluno, dando oportunidade para que o mesmo coloque em prática suas ideias.

Não entregar pronto para o aluno. Ele vai organizar e construir.

\section{Professor}

Promover a permanente atualização pedagógica de nossos professores através do projeto de formação continuada da equipe docente.

Através do respeito ao trabalho desenvolvido pelo professor.

Tabela 4. Propostas Previstas no Projeto Pedagógico para Promover a Criatividade do Aluno Apresentadas pelos Gestores que Responderam Afirmativamente à Questão 3

\begin{tabular}{|c|c|c|c|c|c|c|}
\hline \multirow{3}{*}{ Categorias } & \multicolumn{4}{|c|}{ Tipo de Escola } & \multirow{2}{*}{\multicolumn{2}{|c|}{$\begin{array}{c}\text { Total } \\
(n=118)\end{array}$}} \\
\hline & \multicolumn{2}{|c|}{$\begin{array}{l}\text { Pública } \\
(n=96)\end{array}$} & \multicolumn{2}{|c|}{$\begin{array}{c}\text { Particular } \\
(\mathrm{n}=22)\end{array}$} & & \\
\hline & $f$ & $\%$ & $f$ & $\%$ & $f$ & $\%$ \\
\hline Atividades diversificadas & 52 & 70,27 & 11 & 42,31 & 63 & 63,00 \\
\hline Alunos & 14 & 18,92 & 5 & 19,23 & 19 & 19,00 \\
\hline Professor & - & 0 & 2 & 7,69 & 2 & 2,00 \\
\hline Outras & 8 & 10,81 & 8 & 30,77 & 16 & 16,00 \\
\hline Total & 74 & 100 & 26 & 100 & 100 & 100 \\
\hline
\end{tabular}

Tabela 5. Propostas Apresentadas por Gestores de Instituições Públicas e Particulares de Ensino para Eliminar Fatores que Dificultam ao Professor Favorecer o Desenvolvimento da Criatividade dos Alunos

\begin{tabular}{|c|c|c|c|c|c|c|}
\hline \multirow{3}{*}{ Categorias } & \multicolumn{4}{|c|}{ Tipo de Escola } & \multirow{2}{*}{\multicolumn{2}{|c|}{$\begin{array}{c}\text { Total } \\
(n=118)\end{array}$}} \\
\hline & \multicolumn{2}{|c|}{$\begin{array}{c}\text { Pública } \\
(n=96)\end{array}$} & \multicolumn{2}{|c|}{$\begin{array}{l}\text { Particular } \\
\quad(n=22)\end{array}$} & & \\
\hline & $f$ & $\%$ & $f$ & $\%$ & $f$ & $\%$ \\
\hline Formação/Capacitação & 21 & 16,41 & 10 & 30,30 & 31 & 19,25 \\
\hline Orientação/Apoio/Incentivo & 20 & 15,62 & 5 & 15,16 & 25 & 15,53 \\
\hline Recursos Didáticos/Materiais/Humanos & 17 & 13,28 & 2 & 6,06 & 19 & 11,80 \\
\hline Reflexões sobre a Prática/ Troca de Experiências & 12 & 9,37 & 1 & 3,03 & 13 & 8,07 \\
\hline Alunos & 20 & 15,62 & 4 & 12,12 & 24 & 14,91 \\
\hline Família & 8 & 6,26 & 1 & 3,03 & 9 & 5,59 \\
\hline Tempo/Incentivos Salariais & 6 & 4,69 & - & - & 6 & 3,73 \\
\hline Outras & 24 & 18,75 & 10 & 30,30 & 34 & 21,12 \\
\hline Total & 128 & 100 & 33 & 100 & 161 & 100 \\
\hline
\end{tabular}




\section{Outras}

Interdisciplinaridade entre conteúdos, as coordenações pedagógicas, temas transversais, a contextualização.

Este ano letivo foi implantado a educação integrada, representada pelo projeto que contempla os alunos do $3^{\circ}$ ano, em defasagem idade-série. Foi a forma encontrada pela escola de melhorar o desempenho das crianças.

A análise das respostas obtidas à quarta questão aberta "Como eliminar os fatores que o(a) senhor(a) considera que têm dificultado ao professor favorecer o desenvolvimento da capacidade de criar de seus alunos, apontados na página anterior?" indicou que as mesmas se enquadravam nas categorias relacionadas na Tabela 5. A categoria com maior número de respostas por parte dos gestores de instituições públicas e particulares de ensino foi Formação/Capacitação ( $f$ Total $=31 ; 19,25 \%)$, seguida da categoria Orientação/ Apoio/Incentivo $(f$ Total $=25 ; 15,53 \%)$. Dezenove gestores de instituições públicas deixaram de responder a questão e quatro deram respostas desconexas, como, por exemplo, "para troca de ideias e a equipe pedagógica voltar o horário que era antes para o professor poder coordenar coletivas". Verificou-se ainda que, entre os gestores de instituições particulares de ensino, um não respondeu à questão, e dois responderam que os fatores que dificultam o desenvolvimento da criatividade não podem ser eliminados. Ademais, dois gestores de instituições públicas sinalizaram que eliminar fatores que dificultam o desenvolvimento da criatividade dos alunos é uma tarefa complicada, e que não depende somente da gestão da instituição. Foram três os gestores de instituições públicas que, a esse respeito, indicaram que muitas dificuldades se devem a empecilhos impostos pelas instâncias governamentais às quais a direção da escola está subordinada.

Seguem exemplos de respostas que ilustram cada uma das categorias.

\section{Formação/Capacitação}

Em relação ao profissional, devem-se oferecer cursos de capacitação para que possam sentir-se seguros nas ações a serem desenvolvidas.
Capacitação contínua dos professores em suas práticas docentes.

\section{Orientação/Apoio/Incentivo}

Acompanhamento, trabalho preventivo e de apoio durante todo o tempo.

Por meio de incentivo dos professores e muitas vezes apoio psicológico.

Dar suporte pedagógico no sentido de articular novas práticas.

\section{Recursos Didáticos/Materiais/Humanos}

Receber mais recursos financeiros para equipar melhor as escolas.

Fornecer mais recursos materiais e humanos.

\section{Reflexões sobre a Prática/Troca de Experiências}

Falar mais sobre o assunto e pensando junto com os professores de cada disciplina como eles podem estar estimulando a criatividade.

Oferecer espaço de discussão e reflexão sobre o assunto.

Proporcionar momentos coletivos em que o grupo entre em consenso quanto a essas práticas.

\section{Alunos \\ Redução do número de alunos em sala de aula. \\ Trabalhar a realidade do aluno em seu contexto sociocultural.}

\section{Família}

Trazer sempre para a escola o responsável do aluno, através de reuniões, palestras e encontros promovendo a aproximação constante entre família e escola.

Comprometimento da família para com os alunos.

Escola de pais para promover a participação da família na vida escolar do aluno.

\section{Tempo/Incentivos Salariais}

Aumento salarial.

Redução da carga horária de regência de classe.

Tabela 6. Diferenças Significativas entre Gestores de Instituições Públicas e Particulares Quanto aos Fatores que Dificultam ao Professor Promover o Desenvolvimento da Criatividade dos Alunos

\begin{tabular}{|c|c|c|c|c|c|c|}
\hline \multirow{3}{*}{ Barreiras } & \multicolumn{4}{|c|}{ Instituições de Ensino } & \multirow{3}{*}{$\chi^{2}$} & \multirow{3}{*}{$p$} \\
\hline & \multicolumn{2}{|c|}{ Pública } & \multicolumn{2}{|c|}{ Particular } & & \\
\hline & $f$ & $\%$ & $f$ & $\%$ & & \\
\hline Formação/Capacitação & 21 & 16,41 & 10 & 30,30 & 31 & 19,25 \\
\hline Orientação/Apoio/Incentivo & 20 & 15,62 & 5 & 15,16 & 25 & 15,53 \\
\hline Recursos Didáticos/Materiais/Humanos & 17 & 13,28 & 2 & 6,06 & 19 & 11,80 \\
\hline Reflexões sobre a Prática/ Troca de Experiências & 12 & 9,37 & 1 & 3,03 & 13 & 8,07 \\
\hline Alunos & 20 & 15,62 & 4 & 12,12 & 24 & 14,91 \\
\hline Família & 8 & 6,26 & 1 & 3,03 & 9 & 5,59 \\
\hline Tempo/Incentivos Salariais & 6 & 4,69 & - & - & 6 & 3,73 \\
\hline Outras & 24 & 18,75 & 10 & 30,30 & 34 & 21,12 \\
\hline Total & 128 & 100 & 33 & 100 & 161 & 100 \\
\hline
\end{tabular}




\section{Outras}

Adotar aulas de reforço (eliminando dúvidas).

Atuar na causa dos problemas que dificultam a capacidade criativa dos alunos

Ao se analisarem as diferenças entre gestores de instituições públicas e particulares de ensino nos fatores considerados entraves ao professor para promover o desenvolvimento da criatividade discente, observou-se que um percentual significativamente superior de gestores de instituições públicas, comparativamente ao de escolas particulares, indicou os seguintes fatores: elevado número de alunos em sala de aulas e presença de alunos indisciplinados que perturbam o trabalho docente. Por outro lado um percentual significativamente superior de professores de escolas particulares apontou: poucas oportunidades para o docente discutir e trocar ideias com colegas sobre estratégias de ensino; desconhecimento de textos (livros e/ou artigos) a respeito de como implementar a criatividade em sala de aula por parte do professor; e extensão do programa a ser cumprido no decorrer do ano letivo (ver Tabela 6).

\section{Discussão}

Um dos objetivos deste estudo foi examinar a percepção de gestores acerca das barreiras enfrentadas pelos professores para o desenvolvimento da criatividade discente. No que diz respeito aos entraves à criatividade, os resultados sinalizaram que os participantes os atribuíam especialmente a fatores relacionados ao professor, como desconhecimento e insegurança para implementar práticas pedagógicas favoráveis ao potencial criativo, conhecimento limitado da literatura na área e pouco entusiasmo pela atividade docente, aspectos esses também constatados por Oliveira e Alencar (2010) em estudo com nove gestores de escolas do ensino fundamental da rede pública. Os itens relativos a condições de trabalho e estrutura curricular foram muito pouco mencionados pelos participantes. Neste sentido, a promoção da criatividade no contexto escolar, segundo a percepção destes profissionais, ainda está pautada na figura do professor, ficando em segundo plano o papel do ambiente no estabelecimento de condições que inibem ou dificultam uma atuação criativa por parte do docente. Modelos teóricos que procuram explicar o desenvolvimento da criatividade nos mais diversos contextos sugerem uma abordagem interativa de fatores individuais e ambientais. Renzulli (1992), por exemplo, atrela a produção criativa no processo de ensino/ aprendizagem a aspectos relacionados ao professor, ao aluno e ao currículo. Assim, apesar do professor desempenhar um papel fundamental no desenvolvimento da criatividade em sala de aula, é preciso considerar a influência de outros fatores neste processo. É importante que profissionais que supervisionam ou orientam o trabalho do professor tenham acesso a informações atualizadas acerca do fenômeno da criatividade.

Ao se comparar gestores de instituições públicas e particulares, notou-se que os primeiros tendiam a atribuir mais ao aluno as dificuldades encontradas pelo professor para desenvolver a criatividade. Por outro lado, os das escolas particulares apontavam as condições de trabalho e estrutura curricular como obstáculos mais frequentes à criatividade.

As diferenças nas percepções de profissionais de escolas públicas e particulares podem ser entendidas sob vários pontos de vista: clientela de cada tipo de escola, formação continuada do professor oferecida pela rede pública e particular de ensino, estereótipos e preconceitos, entre outros. É interessante notar que esta percepção ocorre também no que diz respeito às dificuldades de aprendizagem - a família ou o aluno são usualmente vistos pela equipe escolar como a fonte do problema (Collares \& Moysés, 1996; Neves, 1994). Os fenômenos observados no contexto da escola são avaliados de uma maneira unidimensional, sendo desconsiderada a multiplicidade de fatores que influenciam na sua ocorrência e desenvolvimento.

Gestores foram também inquiridos a respeito do que poderiam fazer para auxiliar o professor a desenvolver a criatividade dos alunos. Os aspectos mais ressaltados foram apoio psicológico e material. Quando questionados sobre que práticas pedagógicas o docente poderia utilizar em sala de aula a fim de estimular as habilidades criativas, os profissionais salientaram a necessidade de diversificar as atividades escolares com vistas a motivar o aluno (ex: dinâmicas, atividades artísticas, feiras culturais, passeios etc). Os dados sugerem que, de acordo com a percepção de gestores, a responsabilidade pela promoção da criatividade recai quase que exclusivamente sobre o professor. Outros aspectos que poderiam influenciar a produção criativa em sala de aula, como estrutura curricular, condições de trabalho, formação e capacitação continuada dos próprios gestores, projeto político-pedagógico, não foram elencados pelos participantes. Observa-se, também, um conhecimento limitado acerca de técnicas e estratégias de estimulação da criatividade, uma vez que as respostas apresentadas apontam práticas pedagógicas gerais e rotineiras, sem qualquer embasamento científico na área de criatividade. Resultado semelhante foi obtido por Fleith (2000) ao perguntar professores do ensino fundamental sobre práticas encorajadoras do potencial criativo em sala de aula.

A grande maioria dos gestores afirmou que o projeto político-pedagógico da escola em que trabalham contempla e incentiva a criatividade. Entretanto, ao ilustrar como esse projeto valoriza a criatividade, as respostas focaram, novamente, em atividades diversificadas, gerais, sem especificar como estão relacionadas ao fenômeno criativo (ex: feiras, laboratório de aprendizagem, oficina de esportes etc). Para eliminar fatores que dificultam a promoção da criatividade em sala de aula, os participantes sugeriram, em primeiro lugar, investimento na formação e capacitação dos professores, seguido de apoio ao docente por parte da equipe da escola e do governo. De fato, a formação docente ainda apresenta lacunas, pois tende a valorizar conhecimentos já adquiridos ao invés de se incentivar novas estratégias de solução de problemas, e a enfatizar mais o aluno ideal do que o real, segundo Wechsler e Nakano (2011). Contudo, nota-se uma percepção simplificada dos participantes do estudo acerca da complexidade envolvida na superação dos obstáculos ao desenvolvimento da criatividade no contexto escolar. Capacitar os professores certamente é um aspecto si ne qua non, porém insuficiente, para a promoção de condições 
favoráveis à criatividade em sala de aula. Por se tratar de um fenômeno multidimensional, fatores como condições de trabalho, relações interpessoais, estrutura escolar, parceria escola e família, entre outros, devem também ser considerados.

Renzulli (1992) ressalta que entre os fatores que promovem a aprendizagem criativa estão o romance do professor com o trabalho docente e o domínio do conteúdo ministrado. Amabile (1996) chama atenção para o fato de que um ambiente social estimulador é essencial para o desenvolvimento não só de atitudes e habilidades criativas, como também de motivações. Essa autora lembra também, com base em suas pesquisas em distintos tipos de organizações, que é muito mais frequente ser a criatividade sufocada do que estimulada (Amabile, 1999).

Com vistas a ampliar a compreensão acerca dos fatores inibidores e facilitadores da criatividade em sala de aula, buscamos ir além da percepção dos professores e alunos. Nosso objetivo foi "ouvir" o que gestores pensam sobre tais fenômenos, já que não é possível estabelecer condições favoráveis à promoção da criatividade sem considerar a percepção dos demais profissionais que atuam na escola e que influenciam no trabalho do professor. Chamou-nos a atenção o elevado número de participantes que deixou de responder às questões abertas, o que pode ser uma sinalização de sua falta de familiaridade com o tema.

A presente pesquisa, em que pese sua contribuição para ampliar o conhecimento a respeito do tema focalizado, tem limitações. Uma delas diz respeito à coleta de dados, feita tanto de forma individual quanto coletiva. Isso ocorreu, contrário ao planejado, com o intuito de assegurar um número mais expressivo de participantes. Uma segunda limitação foi ter sido utilizada uma amostra de conveniência e com um número desbalanceado de gestores dos dois tipos de escola. Tais fatores limitam a possibilidade de generalização dos resultados. Para estudos futuros, sugere-se uma amostra mais equilibrada de participantes de instituições de ensino pública e particular, o uso de entrevistas para aprofundamento dos aspectos examinados e a investigação tanto da percepção de outros segmentos da sociedade que têm interface com a escola, como a família, quanto de projetos políticos pedagógicos de escolas, com vista a identificar, em seus objetivos e propostas, a extensão em que o desenvolvimento da criatividade estaria sendo contemplada. Acrescenta-se a essas possibilidades, o exame de novas variáveis para ampliar a compreensão de um fenômeno tão complexo como criatividade. No que diz respeito às implicações práticas, este estudo sinaliza a necessidade de, nos cursos de graduação em Pedagogia e licenciaturas, se incluir a criatividade como tema a ser amplamente tratado, tanto de forma teórica como prática. da pesquisa, Recomenda-se ainda a divulgação de textos com embasamento científico, bem como a realização de oficinas e minicursos que esclareçam e orientem não apenas gestores, mas também coordenadores pedagógicos, professores e demais membros da equipe de profissionais que atuam na escola, sobre criatividade e como favorecer a sua expressão no trabalho pedagógico. Ademais, dada a relevância do tema focalizado na pesquisa e escassez de estudos empíricos, considera-se que muito mais necessita ser investigado a respeito de fatores facilitadores e inibidores à criatividade no ensino fundamental, na perspectiva não apenas de gestores educacionais mas também dos demais componentes da equipe escolar. O presente estudo constituiu apenas um passo nessa direção.

\section{Referências}

Alencar, E. M. L. S. (1995). Criatividade. Brasília: Editora da Universidade de Brasília.

Alencar, E. M. L. S. (2001). Criatividade e a educação do superdotado. Petrópolis: Vozes.

Alencar, E. M. L. S. (2007). O papel da escola na estimulação do talento criativo. In D. S. Fleith \& E. M. L. S. Alencar (Eds.), Desenvolvimento de talentos e altas habilidades (pp. 151-162). Porto Alegre: ArtMed.

Alencar, E. M. L. S., \& Fleith, D. S. (2008). Barreiras à promoção da criatividade no ensino fundamental. Psicologia: Teoria e Pesquisa, 24, 59-65.

Alencar, E. M. L. S., \& Fleith, D. S. (2009). Criatividade. Múltiplas perspectivas. Brasília: Editora UnB.

Alencar, E. M. L. S., \& Fleith, D. S. (2010). Criatividade na educação superior. Avaliação, 15, 201-206.

Amabile, T. (1996). Creativity in context. Boulder, CO: Westview Press.

Amabile, T. (1999). Como não matar a criatividade. HSM Management, 3, 110-117.

Bardin, L. (2004). Análise de conteúdo (3a. ed.). Lisboa: Edições 70.

Beghetto, R. A. (2010). Creativity in the classroom. In J. C. Kaufman \& R. J. Sternberg (Eds.), The Cambridge handbook of creativity (pp. 447-466). New York: Cambridge University Press.

Boruchovitch, E., Alencar, E. M. L. S., Fleith, D. S., \& Fonseca, M. S. (2013). Motivação do aluno para aprender: fatores inibidores segundo gestores e coordenadores pedagógicos. ETD - Educação Temática Digital, 15, 425-442.

Carvalho, O., \& Alencar, E. M. L. S. (2004). Elementos favorecedores e inibidores da criatividade na prática docente, segundo professores de Geografia. Psico, 35, 213-221.

Collares, C. A. L., \& Moysés, M. A. A. (1996). Preconceitos no cotidiano escolar: Ensino e medicalização. São Paulo: Cortez.

Craft, A. (2006). Creativity in schools. In N. Jackson, M. Oliver, M. Shaw \& J. Wisdom (Eds.), Developing creativity in higher education (pp. 19-28). London: Routledge.

Cropley, A. J. (1997). Fostering creativity in the classroom: General principles. In M. A. Runco (Ed.), The creativity research handbook (pp. 83-114). Creskill, NJ: Hampton Press.

Cropley, A. J. (2005). Creativity in education \& learning. London: RoutledgeFalmer.

Ediger, M. (2001). The school principal: State standards versus creativity. Journal of Instructional Psychology, 28, 79-83.

Fleith, D. S. (2000). Teacher and student perceptions of creativity in the classroom environment. Roeper Review, 22, 148-153.

Fleith, D. S., \& Alencar, E. M. L. S. (2010). A inter-relação entre criatividade e motivação. In E. Boruchovitch, J. A. Bzuneck \& S. E. R. Guimarães (Eds.), Motivação para aprender (pp. 209-230). Petrópolis: Vozes.

Fredricks, J. A., Alfeld, C., \& Eccles, J. S. (2010). Developing and fostering passion in academic and nonacademic domains. Gifted Child Quarterly, 54, 18-30. 
Jackson, N., Oliver, M., Shaw, M., \& Wisdom, J. (Eds.). (2006). Developing creativity in higher education. An imaginative curriculum. London: Routledge.

Kaufman, J. C., \& Sternberg, R. J. (Eds.). (2006). The international handbook of creativity. New York: Cambridge University Press.

Lück, H. (2000). Gestão escolar e formação de gestores. Em Aberto, 72, 11-32.

Mariani, M. F. M., \& Alencar, E. M. L. S. (2005). Criatividade e trabalho pedagógico segundo professores de História: Limites e possibilidades. Psicologia Escolar e Educacional, 9, 27-36.

Martínez, A. M. (2006). Criatividade no trabalho pedagógico e criatividade na aprendizagem: Uma relação necessária? In M. C. V. R. Tacca (Ed.), Aprendizagem e trabalho pedagógico (pp. 69-94). Campinas: Alínea.

Ministério da Educação. (1997). Parâmetros curriculares nacionais la a 4 a séries. Brasília: SEB/MEC.

Ministério da Educação. (1998). Parâmetros curriculares nacionais 5 a a 8 a séries. Brasília: SEB/MEC.

Ministério da Educação. (2004). Ensino fundamental de 9 anos. Orientações gerais. Brasília: SEB/MEC.

Ministério da Educação. (2010). Diretrizes curriculares para a educação infantil. Brasília: SEB/MEC.

Morgan, S., \& Foster, J. (1999). Creativity in the classroom. Gifted Education International, 14, 29-43.

Neves, M. M. B. J. (1994). Um estudo sobre as causas atribuidas ao fracasso escolar, na $5^{a}$. série, por alunos, pais e professores (Unpublished master's thesis). Universidade de Brasília, Brasília.

Oliveira, Z. M. F., \& Alencar, E. M. L. S. (2007). Criatividade na formação e atuação do professor do curso de Letras. Psicologia Escolar e Educacional, 11, 223-237.
Oliveira, E. L. L., \& Alencar, E. M. L. S. (2010). Criatividade e escola: Limites e possibilidades segundo gestores e orientadores educacionais. Psicologia Escolar e Educacional, 14, 245-260.

Renzulli, J. S. (1992). A general theory for the development of creative productivity through the pursuit of ideal acts of learning. Gifted Child Quarterly, 36, 170-182.

Smith, J. K., \& Smith, L. F. (2010). Educational creativity. In J. C. Kaufman \& R. J. Sternberg (Eds.), The Cambridge handbook of creativity (pp. 250-264). New York: Cambridge University Press.

Smith-Bingham, R. (2006). Public policy, innovation and the need for creativity. In N. Jackson, M. Oliver, M. Shaw, \& J. Wisdom (Eds.), Developing creativity in higher education (pp. 10-18). London: Routledge.

Souza, M. E., \& Alencar, E. M. L. S. (2006). O curso de pedagogia e as condições para o desenvolvimento da criatividade. Psicologia Escolar e Educacional, 10, 21-30.

Torrance, E. P. (1995). Why fly? A philosophy of creativity. Norwood, NJ: Ablex.

Vianna, C. R. G. V., \& Alencar, E. M. L. S. (2006). Creativity and barriers to its expression in online education courses. Gifted Education International, 21, 54-62.

Wechsler, S. M. (2001). A educação criativa: Possibilidades para descoberta. In S. Castanho \& M. E. Castanho (Eds.), Temas e textos em metodologia do ensino superior (pp. 165-170). Campinas: Papirus.

Wechsler, S. M., \& Nakano, T. C. (2011). Criatividade: Encontrando soluções para os desafios educacionais. In S. M. Wechsler \& V. L. T. Souza (Eds.), Criatividade e aprendizagem (pp. 11-31). São Paulo. Edições Loyola.

Wechsler, S. M., \& Souza, V. L. T. (Eds.). (2011). Criatividade e aprendizagem. São Paulo. Edições Loyola.

Recebido em 08.04.2013

Primeira decisão editorial em 08.11.2013

Versão final em 14.12.2013

Aceito em 04.12.2013 